\title{
TREPHINING (1) FOR CEREBRAL CYST; (2) FOR UNCOMPLICATED WORD-BLINDNESS.
}

\author{
By WILLIAM IRELAND WHEELER, M.D., F.R.C.S.; \\ Surgeon City of Dublin Hospital.
}

[Read in the Section of Surgery, April 8, 1892.]

In the latter part of the year 1888 I was requested to see a lady from the south of Ireland, stated to be suffering from an "ascending cortical degeneration." Her history as I received it is as follows:-In the summer of this year (June) she was subjected to some mental and domestic annoyance, and on one morning about one hour after breakfast she became partly unconscious, her speech was markedly imperfect for some time, and never regained its former perfection. She had loss of power in her right facial muscles, and in her right hand and arm and leg there was impaired motion. This lady rallied after an hour or so, and recovered sufficiently to enable her to visit the Glasgow Exhibition, and, as I am informed, did not express displeasure at her trip.

As she was not improving, but rather the contrary, I was consulted about the end of October, or beginning of November, in the year 1888. The train of symptoms at that time nearly corresponded to what $I$ have recorded above, except that her speech had become more impaired, and the partial paralysis of her leg and arm more apparent.

The subject of this inquiry was about forty-four years of age, of medium statue, sallow complexion; her catamenial periods were regular. She had borne one child, a male-now about twenty-one years of age. Her appetite was good, and her digestive system was unimpaired; her loss of power has been described. The dynamometer registered marked 
difference of power between her right and left hands; there was no loss of sensation by the æsthesiometric test. There was an appreciable difference of temperature between the impaired and unimpaired limbs as measured by a surface thermometer. Her hearing was normal, as also her vision. Her response was slow and with hesitancy; she generally found the right words in reply, and yet occasionally misapplied a word; she could read the newspaper imperfectly, and could generally spell a word that she did not know, yet not pronounce it; when named she could repeat it; her pantomimic speech was not much impaired, if at all. She was unable to write perfectly from dictation, omitting letters at the end and middle of her words, and when writing from a copy with similar results, one example will suffice. The late Dr. Corley, who saw her with me in consultation, and asked her to write as follows:-Tell Mr. Wheeler to call to-morrow. She wrote-Tell Mr. Doe to ca tomo-rw. She could, however, write her name perfectly and correctly. Not unfrequently she complained of shooting pains in the left side of her head, and sometimes upon the right side. Occasionally there was some slight loss of appetite; upon some occasions she walked better than others-she might walk very well upon a Monday, and on Wednesday the drag in her leg would be much more marked. For reasons hereafter, I advised operation, but in this the late Dr. Corley, whom I had met in consultation, could not coincide.

Dr. Fitzgerald, who examined her eyes, could not find anything wrong with vision. I had previously examined her sight with similar results. Nothwithstanding the high opinion I entertained for Dr. Corley's sagacity and diagnostic skill, a week after I was constrained to reiterate my opinion, which I believe would have been acceded to by her sister, who was in constant attendance, but for the advice of a practitioner who saw her in consultation in the country, and who, happen- 
ing to be in Dublin at the time, through my courtesy saw her with me, and stated to her sister, as repeated to me, and tapping his hat, not then upon his head, said that fluid might as well be taken from beneath it.

Matters were pretty much the same in the following February, 1889. As I had to go to London for two or three days, I suggested to the lady and her sister to have another opinion, and they gladly assented. An examination was held by a gentleman whose name is a sufficient guarantee for his accuracy in cerebral affections and cerebral lesions. The arrangement which I suggested was, that there should not be any consultation, but an opinion expressed withont conference. The opinion advised that change of air and tonic treatment should be tried, \&c. I then stated that I had strongly expressed the necessity for operation, but his opinion was not materially altered. Upon her visit to London it was ascertained that she was suffering from hemianopsia. On her return I made further examination, and for the first time I ascertained she was suffering from loss of smell on the left side. I was more confirmed in my opinion, and again expressed it. I ordered her to Bray for change, and prescribed a tonic, from which there was not any improvement. On the contrary, the patient grew worse, both in her articulate and written speech, and in her gait, and what may be called apperception. Finally she got paralysis of both lower and upper limbs, total aphemia, and pantomimic speech was eventually lost. It was now nearly six months since I had advised operation, and even now as a dernier réssort I still recommended it, and at the eleventh hour it was consented to.

Upon Easter Sunday, 1889, the patient being under the influence of chloroform, assisted by Dr. Duffey and Dr. Corley and Dr. Harley, I trephined over the left parietal eminence. Immediately upon the bone being removed, the membranes 
bulged out even beyond the surface of the calvarium. I shall not detail the operative measures, save one, particularly-that is, the incision in the dura mater. I usually make this circularly round the margin of the trephine opening, and not too close to the edge of the bony aperture, and not completely round, but leaving interspaces. The advantage of this method over the crucial incision is that, when the membrane is being readjusted the firmest pressurc is over the centre of the brain exposed in the aperture, and where the brain most usually protrudes. By not going too close to the edge of the aperture, it leaves sufficient room to apply sutures through both sides of the serered dura mater. This is worthy of notice, and not unimportant in cases where it may not be desirable to replace the bone. Upon raising the membrane, and exploring with a syringe needle, I obtained fluid (here produced). I regret that circumstances have prevented Dr. Duffey being present here to-night, to whom I stated that fluid would be obtained, and who could tell that I had written beforehand what I should most likely find. My statement was justified, no less than 4 ozs. of fluid having been concealed.

The result of the operation was encouraging. The patient, within less than half an hour, spoke slowly; an example will best explain. Her husband entered the apartment, holding a telegram in his hand; she exclaimed, "Whom is that telegram from?" he replied, "It is from that Mr. Blank." She replied, "Is that Mr. Blank, of-__ ; what does he want?" Within one hour her left arm recovered power, and the right arm as well as it was previously to the total loss of power. Towards evening of the day after Monday her left leg partially recovered, her right leg did not improve, and pantomimic speech was present until 'Thursday. She died upon Friday, five days after the operation, about six months after I had first recommended it. 
I had intended to allude to a case of pure uncomplicated word-blindness-which affection is not often met with-as several points in this case could with advantage be contrasted with the first case, but time would not permit--the contrast must be postponed. Suffice it to say that I trephined in the same region, and evacuated pus, with the result of an excellent and continued recovery now two and a half years ago.

In considering the unfortunate case which $I$ have recorded, and which was lost through procrastination, it had occurred to me that, on account of the pain in the side of her head and ear, possibly the want of power in the limbs might be caused by irritation in the medulla oblongata-perhaps a local phlebitis of the vessels of the medulla as the acoustic vein joins the veins upon the anterior of the medulla oblongata-and that the right facial paralysis was caused by the irritation of the centre of the seventh nerve, and that the defect in her speech was likely due to the fibres of the left restiform body running upwards. But this idea was early dissipated from my mind, and upon further reflection I localised the lesion at the site of the operation, and in coming to this conclusion I was much assisted by the train of the phenomena, and by the exclusion of many lesions suggestive as causing the disorders. That it was not purely motor aphasia, even in the very advanced stage, was evident. There was no bulbar paralysis, for there was no difficulty of deglutition, and no labio-glosso pharyngeal paralysis.

$I$ did not suspect a tumour-first, because of the absence of optic neuritis, although optic neuritis is frequently absent although a tumour may exist; secondly, by reason of the suddenness of the attack and the rally; thirdly, because $\mathbf{I}$ have found that in fluid collections in the brain, associated with aphasia, change of position not unfrequently relieves pain and occasionally improves articulate speech, but not 
written speech. Besides aphasia and its various modifications, and agraphia with its modifications, and amnesia, this patient also was the subject of apperceptive aphasia. As this lesion is situated in the surroundings of the branches of the Sylvian artery, it also was a source of help in localising the site for trephining, which was not arrived at without careful thought, together with much toil and reflection.

Dr. Harlex said, as one of those who was present at this operation, and witnessed the very marked result of it, he might be permitted to say a few words-chiefly in corroboration of what Mr. Wheeler had described to them. As it had occurred that this patient had been on several occasions under his care during temporary absences of Mr. Wheeler, he was fully aware of the state she was in before he saw her on the table, and could better realise the sudden return of consciousness and motor power, not only in remarking in her husband's hand the telegram, and asking from whom it came, but before he (Mr. Harley) left the room she had put her hand up to her head. The late Dr. Corley was present, and he thought his (Dr. Corley's) delight, when he saw the fluid in the aspirating needle, was quite equal to that of $\mathrm{Mr}$. Barton when he saw the pus, in his case of "Aneurysm or Abscess," just read by him.

Mr. Wheeler, in reply, could not state exactly what the lady died of, as an examination was not granted. Her death, he believed, was reported as from syncope. In his experience convulsions were not common in cysts of the brain, as above described. 